\title{
The Structure and Evolution of Sea Breezes During the Qingdao Olympics Sailing Test Event in 2006
}

\author{
SHENG Chunyan ${ }^{* 1,2}$ (盛春岩), Ming XUE ${ }^{3,4}$, and GAO Shouting ${ }^{5}$ (高守亭) \\ ${ }^{1}$ Shandong Provincial Meteorological Observatory, Jinan, Shangdong 250031 \\ ${ }^{2}$ Shandong Provincial Meteorological Institute, Jinan, Shangdong 250031 \\ ${ }^{3}$ School of Meteorology, University of Oklahoma, Norman, Oklahoma 73072, USA \\ ${ }^{4}$ Center for Analysis and Prediction of Storms University of Oklahoma, Norman, Oklahoma 73072, USA \\ ${ }^{5}$ Laboratory of Cloud-Precipitation Physics and Severe Storms, Institute of Atmospheric Physics,
} Chinese Academy of Sciences, Beijing 100029

(Received 10 December 2007; revised 10 May 2008)

\begin{abstract}
Using data from automatic surface weather stations, buoys, lidar and Doppler, the diurnal variation and the three-dimensional structure of the sea breezes near the sailing sites of the Good Luck Beijing2006 Qingdao International Regatta from 18 to 31 August 2006 are analyzed. Results show that excluding rainy days and days affected by typhoon, the sea breezes occur nearly every day during this period. When Qingdao is located at the edge of the subtropical high at $500 \mathrm{hPa}$, the sea breeze is usually stronger, around $3-4 \mathrm{~m} \mathrm{~s}^{-1}$. It starts at around 1100 to 1300 LST and lasts about 6 hours. The direction of the sea breeze tends to be southeasterly. When Qingdao is under the control of the subtropical high, the sea breeze is usually weaker, less than $2.5 \mathrm{~m} \mathrm{~s}^{-1}$ throughout the day, and begins later, between 1300 and 1500 LST. In this case, the direction of the sea breeze is variable from easterly to southeasterly.

Most sea breezes in Qingdao are very shallow, up to 300 meters deep. Strong sea breezes can reach 1.5 $\mathrm{km}$ in depth and can push as far as $100 \mathrm{~km}$ inland. If the Huanghai sea breeze moves inland and meets the sea breeze of the Jiaozhou Bay in the western part of Qingdao, the sea breeze will strengthen and form three boundaries due to the interaction of the two sea breezes.
\end{abstract}

Key words: Olympic sailing, sea breeze, local coastal winds

Citation: Sheng, C. Y., M. Xue, and S. T. Gao, 2009: The structure and evolution of sea breezes during the Qingdao Olympics sailing test event in 2006. Adv. Atmos. Sci., 26(1), 132-142, doi: 10.1007/s00376009-0132-y.

\section{Introduction}

The sea and land breezes refer to near surface winds that blow from the sea to land during daytime and from land to sea at night caused by uneven surface heating. Within the weather forecasting community in China, the sea and land breezes have not received much attention from forecasters due to limited availability of real-time detailed observations. For the Olympic sailing events to occur near Qingdao, a coastal city in eastern China, in 2008, sea breeze fore- cast is very important because the wind speed error needs to be within $1 \mathrm{~m} \mathrm{~s}^{-1}$ and the wind direction error within 50 degrees. In August, the wind is often under $3 \mathrm{~m} \mathrm{~s}^{-1}$ in Qingdao, so the influence of sea breeze is very important. In order to provide better weather forecast services for the 2008 Olympic sailing events, several tens of automatic weather stations have been set up over the past two years near the sailing spots and in the coastal region of Qingdao, and three buoys were established at sailing spots A, B and C (see Fig. 1). With these data, the sea and land breezes near the

\footnotetext{
*Corresponding author: SHENG Chunyan, scy@mail.iap.ac.cn
} 


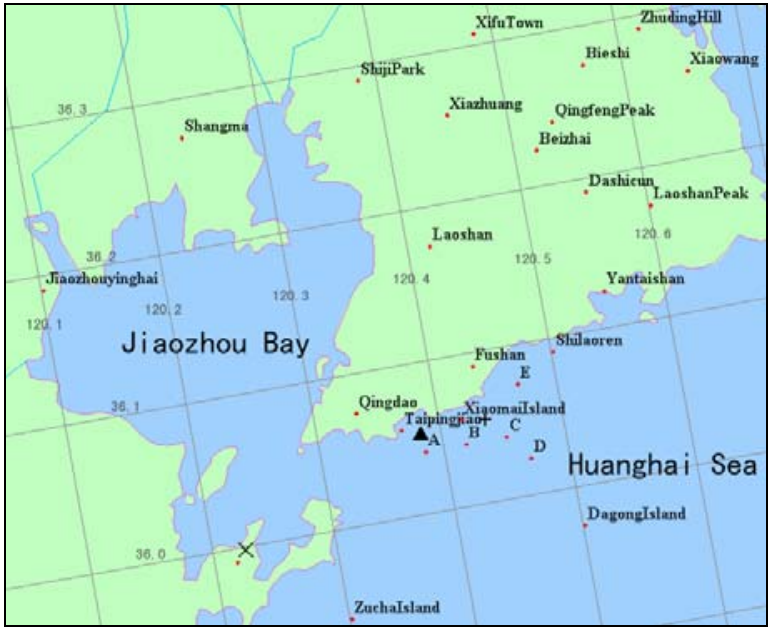

Fig. 1. Geographical map of Qingdao and its neighboring regions. Station sites (buoys and AWS) near Qingdao 2008 Olympic sailing spots (" $\times$ " is the location of Huangdao Doppler radar, "+" is the location of the lidar at Xiaomai Island)

sailing spots can be studied in detail for the first time.

Studies on the sea and land breezes can be traced back to the 1940s. Simple numerical models were used by Haurwitz (1947) and Defant (1951) to study the fine structure and direction change of sea breezes. These studies found clockwise rotation of sea breeze wind direction with time. In these models, the sea breeze starts at right angles to the coast and veers (moves anticyclonically), until sunset when it blows nearly parallel to the coastline. Numerical models with complex forcing have shown cyclonic rotation, and Neumann (1977) gave three reasons why the change of the sea-breeze direction was non-uniform with time. This was due to three principal terms: (1) Coriolis (unknown from previous work); (2) pressure gradients due to diurnal heating; and (3) large-scale pressure gradients not affected by diurnal changes. But there are many occurrences where the sea breeze direction doesn't change or even rotates cyclonically, which were explained as the effect of mountains (e.g., Staley, 1957). The detailed structure of sea breeze in the daytime has been studied by, e.g., Sha et al. (1991) and Clarke (1984).

Estoque (1961) found that the formation and strength of the sea breeze was affected by the largescale flow in addition to the heating condition. Many studies have shown that the prevailing synoptic-scale flow has a direct effect on the strength and landward penetration of the sea-breeze front (e.g., Wexler, 1946; Haurwitz, 1947; Defant, 1951; Estoque, 1962; Frizzola and Fisher, 1963; Schroeder et al., 1967; Arritt, 1993; Reible et al., 1993). The details of the resultant struc- ture of the sea-breeze front are still not complete, but several general features are evident. Bechtold et al. (1991) and Arritt (1993) examined sea-breeze frontogenesis and stability for a large range of synoptic wind speed and direction during the day. Zhong and Takle (1993) modeled the influence of the large-scale background flow on mesoscale and microscale aspects of the sea breeze by dividing the sea breeze into two types: those with sea breeze fronts normal to the coastal line and those with fronts parallel to the coastline. The two general classes of sea breezes differed in many respects, including the associated maximum vertical velocities. Reible et al. (1993) found that when the flow is offshore, the sea breeze front is associated with a pronounced discontinuity owing to increased convergence and subsequent frontogenesis. In addition, the offshore flow does not allow the sea breeze front to penetrate far inland. When the synoptic flow is onshore the front is weak but it penetrates much farther inland.

Houghton and Campbell (2005) reviewed many aspects of the sea and land breezes and the forecasting techniques, pointing out that the large-scale wind near the surface can affect the sea breeze significantly. An analysis of sea breezes has been performed in a number of aspects in various works (Frizzola and Fisher, 1963; Barbato, 1975; Wakimoto and Atkins, 1993; Buckley and Kurzeja, 1997; Zhang et al., 2005).

In Qingdao, the weather in August is different from many of other regions where the land and sea breezes are studied. The dominant weather system in this season is the subtropical high pressure system over the western Pacific Ocean. Once Qingdao is under the control of this high at $500 \mathrm{hPa}$, the weather is usually humid, stuffy and calm. At the edge of the high pressure system, there tend to be thundershowers. In China, some studies on sea breezes exist. For example, $\mathrm{Wu}$ and Long (1993) analyzed the local sea breeze features in Qingdao with data from coastal weather stations. Xue et al. (1995) studied the feature of sea breeze in Longkou city on the northern Shandong Peninsula. Zhuang et al. (2005) analyzed the climatic feature of sea and land breezes in Rizhao city with Rizhao coastal data. Jin and Wang (1991) studied the effect of landsea air temperature contrast on the strength of sea breeze with a three-dimensional numerical model and found the dominant effect of the temperature contrast in their cases. Chang et al. (2002) found through 3D numerical simulation that the sea breeze near Qingdao is affected significantly by the heating of Laoshan Mountain. Without marine data, these studies did not provide the fine-scale analysis of sea breeze features near Qingdao. Furthermore, these studies did not look at the effect of large scale flows associated 
with the subtropical high.

Fortunately, several Automatic Weather Stations (AWS) near the coastal region and the islands were established for the 2008 Olympic sailing events. Buoys were set up at sailing spots $\mathrm{A}, \mathrm{B}$, and $\mathrm{C}$, respectively. With these fine-resolution observation data in and near Qingdao, new features and the fine structure of the sea breeze in this region can be observed. Is the sea breeze frequent near the sailing spots? Is the sea breeze near the sailing spots strong? What time does the sea breeze usually begin? In this study, in order to answer these questions, improving the forecasting skill of the sea breeze and offering better meteorological service for the sailing events, the sea breeze during the Olympic sailing test period is studied. The rest of this paper is organized as follows. Section 2 provides a brief introduction to the observing data. Section 3 is an overview of the weather during the period, and section 4 discusses the general features of sea breezes. Section 5 examines the relationship between the sea breezes with the temperature contrasts, section 6 discusses the different features of the two types of sea breezes for the days under the control and at the edge of the subtropical high, and section 7 further examines the $3 \mathrm{D}$ structures of the breezes. A summary is given in the final section.

\section{Brief introduction to the observing data}

The Good Luck Beijing-2006 Qingdao International Regatta, also known as the test event of the 2008 Olympics, was held in the Fushan Bay of Qingdao (see Fig. 1). It was an International Sailing Federation (ISAF) Grade 2 International Regatta, which included 11 events in nine classes. More than 503 world-class athletes from 40 countries participated. The test event was held from 18 to 31 August 2006 and the provision of weather forecasting for the event began on $10 \mathrm{Au}-$ gust.

There are three sailing spots in the Bay area, as marked by A, B, and C in Fig. 1. There is a buoy at each spot. Over thirty automatic weather stations were established in the coastal region. These buoys and AWSs can offer hourly wind, temperature, relative humidity and sea level pressure. On Huangdao Island in the southern part of Qingdao, there is a CINRADSA Doppler radar (Fig. 1), which is a part of the Chinese new generation weather radar net and can offer real time 6-minute Doppler radar products. The lidar in the Ocean University of China was also in-situ during the test event. It is a kind of Doppler windfinding radar and can give the vertical wind profile near the sailing spot. Because the lidar is a new facility, it was tentative during the test event and its data is not continuous. Using available in-situ and remotesensing observations, the wind features from 9 through 31 August are analyzed in this study.

\section{Overview of general weather pattern}

In general, when the ridge of the subtropical high at the $500 \mathrm{hPa}$ level migrates from the ChangjiangHuaihe region to the North China plains, the weather in Qingdao is usually calm and stuffy, and tends to have thundershowers. According to the data from 1971 to 2000, wind speed is the lightest in August in Qingdao. During the 2006 Olympics sailing test event, the dominant weather system was the typical subtropical high. Specifically, the weather pattern of Qingdao can be divided into three types: days when Qingdao is under the control of the subtropical high (to be referred to as CNTL case), at the edge of the subtropical high (to be referred to as EDGE case), and at the edge of a typhoon, respectively. Data show that sea breeze did not occur on rainy days (14 to 16, 25 to 26, 29 and 31 August) and on the days affected by a typhoon (17 and 18 August). The sea breeze occurred on all other days $^{\mathrm{a}}$. In order to study the features of the sea breeze, the sea breeze days are divided into two periods: the first period from 9 to 13 August, during which the area was under the control of the $500 \mathrm{hPa}$ subtropical high (the CNTL case, see Fig. 2a), and the second period from 19 to 31 (excluding rainy days), during which the area was at the edge of the $500 \mathrm{hPa}$ subtropical high (the EDGE case, see Fig. 2c). It is found that under the control of the $500 \mathrm{hPa}$ subtropical high, the SLP is very low and the surface wind is usually southerly (Fig. 2b). At the edge of the $500 \mathrm{hPa}$ high, the SLP is much higher and the surface wind is usually northerly (Fig. 2d).

\section{Observed sea breeze characteristics}

Figures $3 \mathrm{a}$ and $3 \mathrm{~b}$ show the diurnal evolution of mean wind speed at the three buoys for the two weather patterns. It can be seen that there are two wind speed peaks within the diurnal cycle, corresponding to the sea and land breezes, respectively. The land breeze occurs in the early morning hours between 0300 to 0900 LST in both situations ${ }^{b}$. The timing of the

\footnotetext{
${ }^{a}$ Here, the sea breeze is loosely defined as an event with wind direction in the coastal region near the sailing spots changing from synoptic-scale wind direction to easterly, southeasterly or southwesterly at around noon and then turning back to its original direction in the evening.

${ }^{\mathrm{b}} 0800 \mathrm{LST}=0000 \mathrm{UTC}$
} 

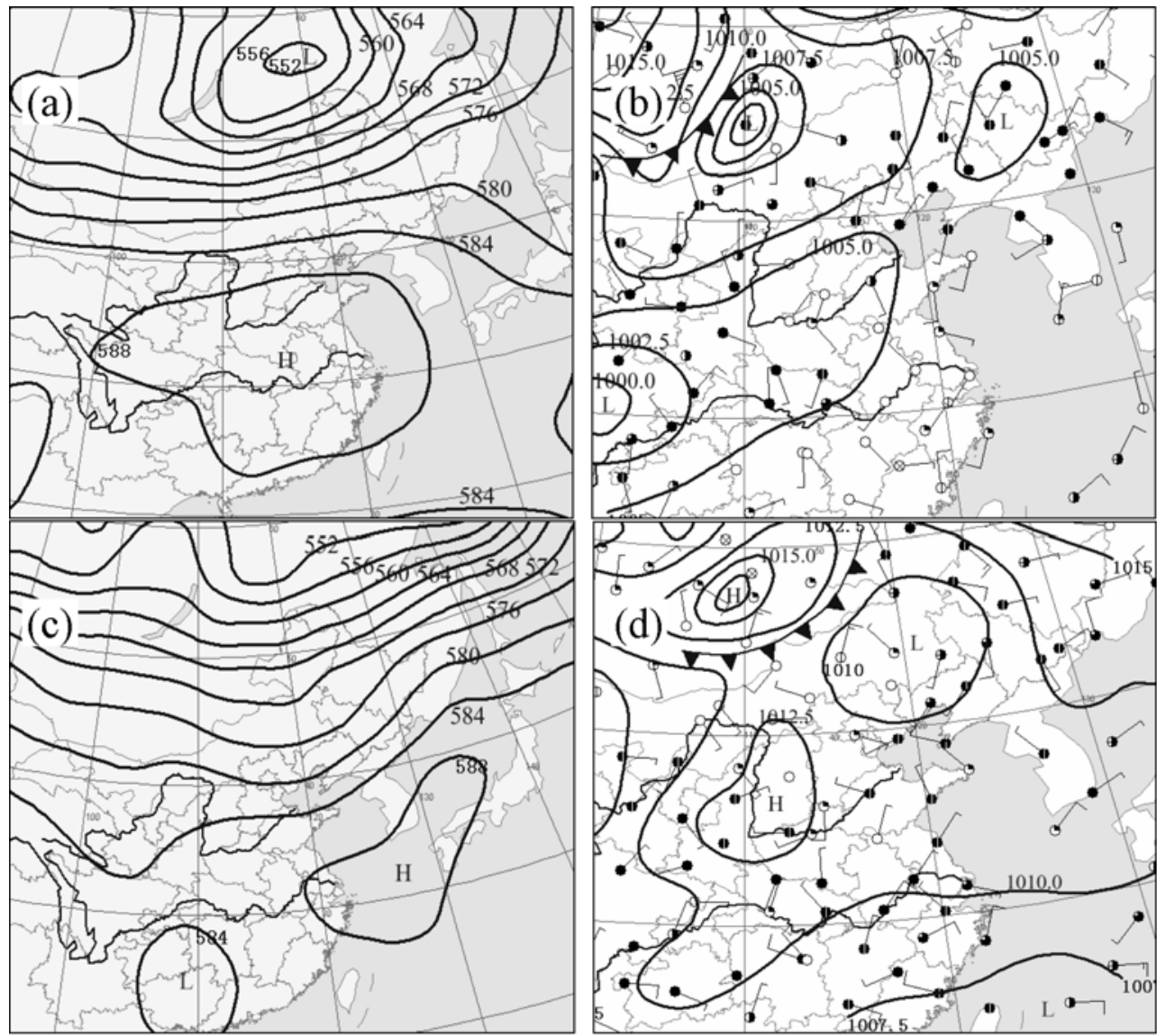

Fig. 2. Example weather patterns for a CNTL at 0800 LST 13 August (a and b) and an EDGE case on 0800 LST 23 August (c and d). Left: 500 hPa pressure pattern (units: gpm), right: surface level pressure $(\mathrm{hPa})$ (The shaded part in the right of the figures is the ocean).

sea breeze differs a lot between the two situations. For the sea breeze under the control of subtropical high (CNTL case), the onset time is between 1300 and 1500 LST, later than the 1100 to 1300 LST onset time found when the region is at the edge of the high (EDGE case). The peak sea breeze wind speed is reached between 1500 and 1600 LST in the former case, while it is reached at or shortly after $1200 \mathrm{LST}$ in the latter case. The sea breeze winds are sustained for 5 to 6 hours in both cases.

In the CNTL situation, the wind is light and the sea breeze is weak, with the mean wind speed at the buoy sites remaining below $2.5 \mathrm{~m} \mathrm{~s}^{-1}$ throughout the day. For the EDGE case, the winds are generally stronger, with the strongest winds of the day being associated with the sea breeze, nearly $4 \mathrm{~m} \mathrm{~s}^{-1}$ at or shortly after noon. The test event occurred from 18 to 31 August, when Qingdao was mainly at the edge of the subtropical high. Considering the requirement of 3 to $18 \mathrm{~m} \mathrm{~s}^{-1}$ wind speed and 50 degrees wind direction error of the forecast accuracy for the sailing event, the sea breeze provides the necessary wind speed and stable wind di- rection for sailing, and that is why the test event can be carried through everyday during the Olympic test events even though the winds were very weak over land in Qingdao.

It can be seen further from Figs. $3 \mathrm{a}$ and $3 \mathrm{~b}$ that the wind speed is strongest at buoy $\mathrm{A}$, the wind speed at buoy $\mathrm{B}$ is stronger, and that at buoy $\mathrm{C}$ is the least. This slight difference of the wind speed can be attributed mainly to the different distance of the buoys from the coast. The wind speed drops quickly when sea breeze ceases. Land breeze turns to sea breeze from 1000 to 1300 LST, with the wind speed decreasing and then increasing again. The sea breeze in the EDGE case develops to a greater strength and weakens quickly after around $1700 \mathrm{LST}$ and the minimum wind speed is reached between 2000 and 2200 LST. After 2200 LST, the wind speed starts to pick up again as the land breeze starts to form in the evening and early morning hours.

The changes in the wind direction are shown in Fig. 3c through Fig. 3f. It can be seen that the wind is weaker and more changeable in the CNTL 

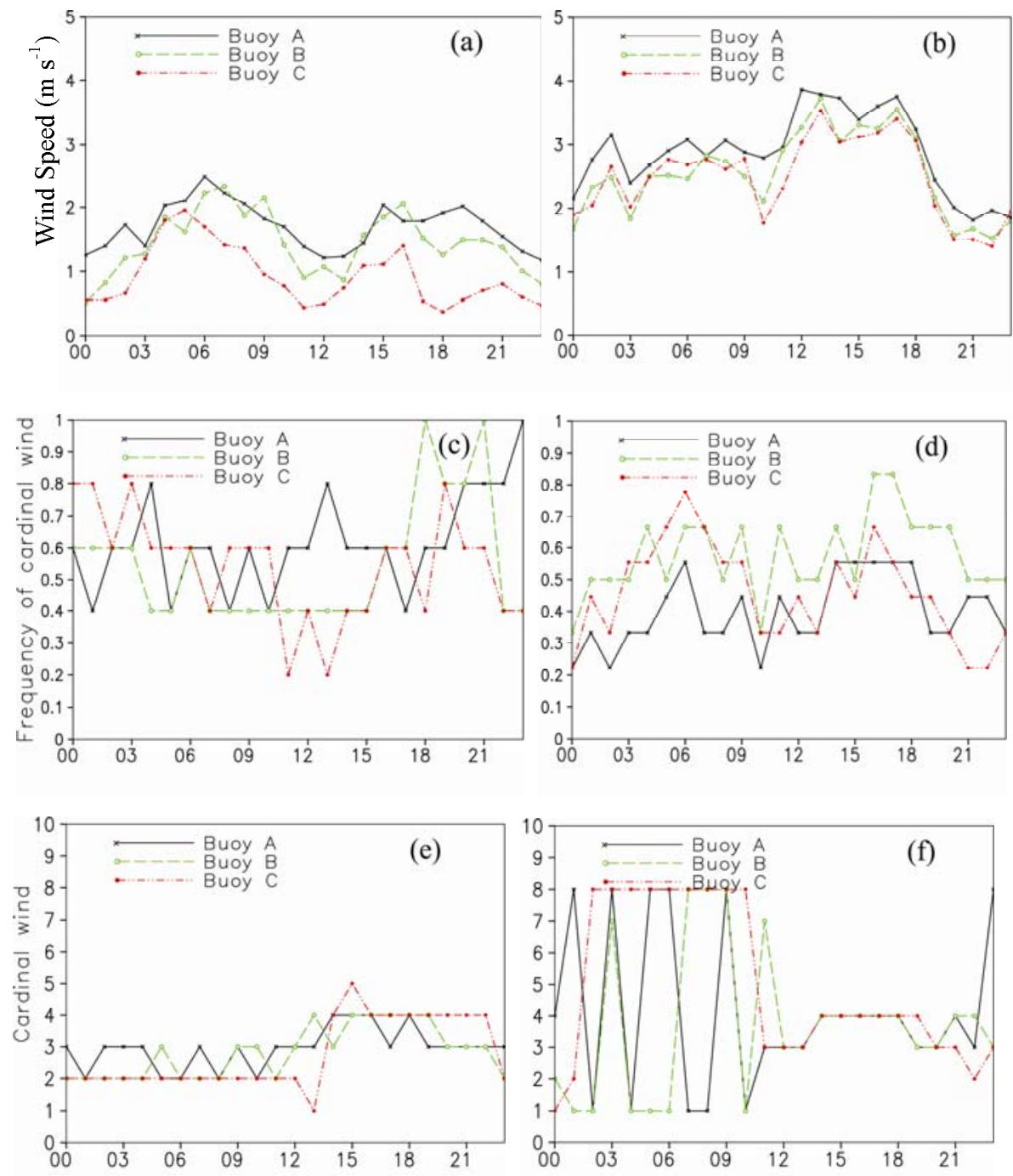

Fig. 3. Wind speed at three buoy stations (a and b) $\left(\mathrm{m} \mathrm{s}^{-1}\right)$, frequency of cardinal wind ( $c$ and $d)$, and the direction of cardinal wind (e and f) at three buoy stations of the sea breeze days during 9 to 31 August 2006 (The wind direction in (e) and (f) are given in 1 through 8, with 1 representing due north, and each increment of 1 representing a 45 degree clockwise increment). The left column is for CNTL cases and the right column is for EDGE cases.

case. The direction of the sea breeze is generally easterly to southeasterly. For the EDGE case, the wind is stronger and the wind direction is more stable. In this situation, the prevailing wind is northerly in the morning and the sea breeze is southeasterly. The direction of the sea breeze is normal to the coastline.

\section{Relation between sea breeze and land-sea air temperature contrast}

To examine the land-sea temperature contrast and its relationship with sea breeze strength, the daily temperatures over the sea (buoys) and land is analyzed.
The Fushan station that is about $2 \mathrm{~km}$ inland from the coast and closest to the buoys (see Fig. 1) is selected to represent the temperature over land. Figures $4 \mathrm{a}$ and $4 \mathrm{~b}$ show the mean diurnal temperatures at the buoys and Fushan for the CNTL and EDGE days. It is found that the temperatures at the three buoys are nearly the same and have a small diurnal change. The temperature over the land increases significantly in day time due to the daytime heating. At night, the temperatures over the land and the sea are nearly the same for CNTL days, which explains the weak land breeze in this type of weather. While in EDGE days, temperatures over land at night are $1^{\circ} \mathrm{C}-2^{\circ} \mathrm{C}$ colder, 

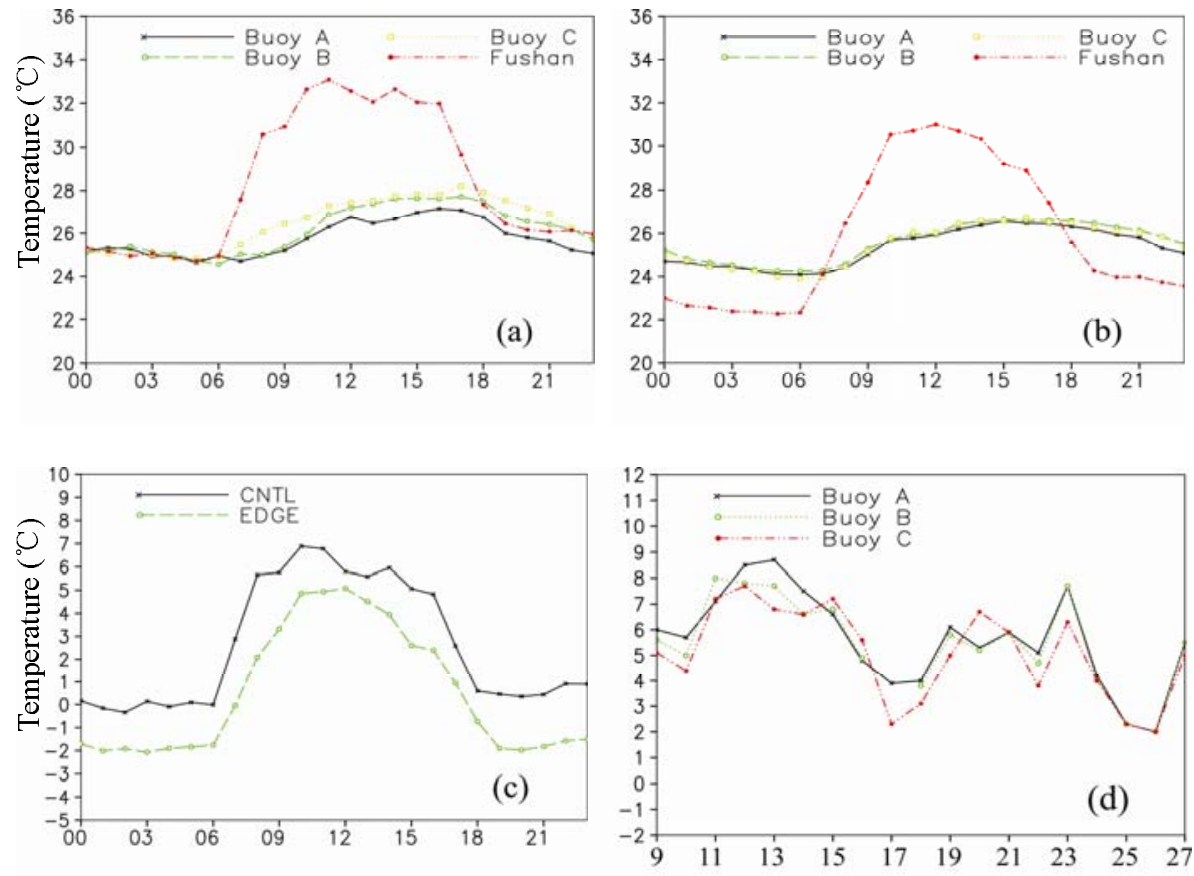

Fig. 4. Mean diurnal temperature over the sea (at three buoy sites) and over land (at Fushan station) for (a) CNTL and (b) EDGE cases, (c) mean daily sea-land temperature difference (land temperature minus sea temperature), and (d) maximum daily temperature differences between each buoy site and Fushan station from 9 to 27 August 2006. Note that data are missing from 28 to 31 August, and the times in $\mathrm{a}, \mathrm{b}$ and $\mathrm{c}$ are in LST.

producing stronger land breezes (see Fig. 4c). As a result, the maximum temperature contrast is generally higher for the CNTL days but is lower for the EDGE days.

Figure $4 \mathrm{~d}$ shows the curves of the daily maximum temperature differences between Fushan and buoys A, $\mathrm{B}$, and $\mathrm{C}$ from 9 to 27 August $^{\mathrm{c}}$. It can be seen that for the sea breeze days, the difference of the temperature is all over $4 \mathrm{~K}$. But the sea-land temperature difference for CNTL days is generally higher than that for the EDGE days. The largest daily maximum temperature contrast appears on 12, 13 and 23 August, which are over $6^{\circ} \mathrm{C}$ at all buoy sites. In fact, the sea breeze is the strongest on 23 August over the entire test period, while the sea breeze is not very strong on 12 and 13 August. The maximum temperature contrast on 13 August is the largest but the maximum wind speed of the day is less than $2.5 \mathrm{~m} \mathrm{~s}^{-1}$. This indicates that the strength of the sea breeze is not only determined by the land-sea temperature difference.

It is found in Fig. 2 that the surface weather systems are quite different on 13 and 23 August. On 13 August the Qingdao area is under the control of a surface low pressure system and the prevailing wind is southerly. While on 23 August, the Qingdao area is under the control of a surface high pressure system and the prevailing wind is northerly, which is the dominant wind direction for the EDGE case. The surface weather system on 12 August is similar to that on 13 August and the prevailing wind is southerly too. Because the sea breeze is a shallow thermal circulation, the return circulation of the sea breeze in Qingdao is nearly northwesterly. Therefore, the northerly prevailing wind for the EDGE case can help the establishment of the sea breeze return circulation and the sea breeze is stronger.

\section{Three-dimensional structure of sea breeze}

\subsection{Vertical structures of sea breezes from Doppler radar Velocity Azimuth Display (VAD) wind profiles and lidar wind pro- files}

Figure 5a shows the time-height cross section of wind profiles derived from lidar measurements located at Xiaomai Island between the coastline and the sailing sites for the afternoon of 21 August (see Fig. 1). 


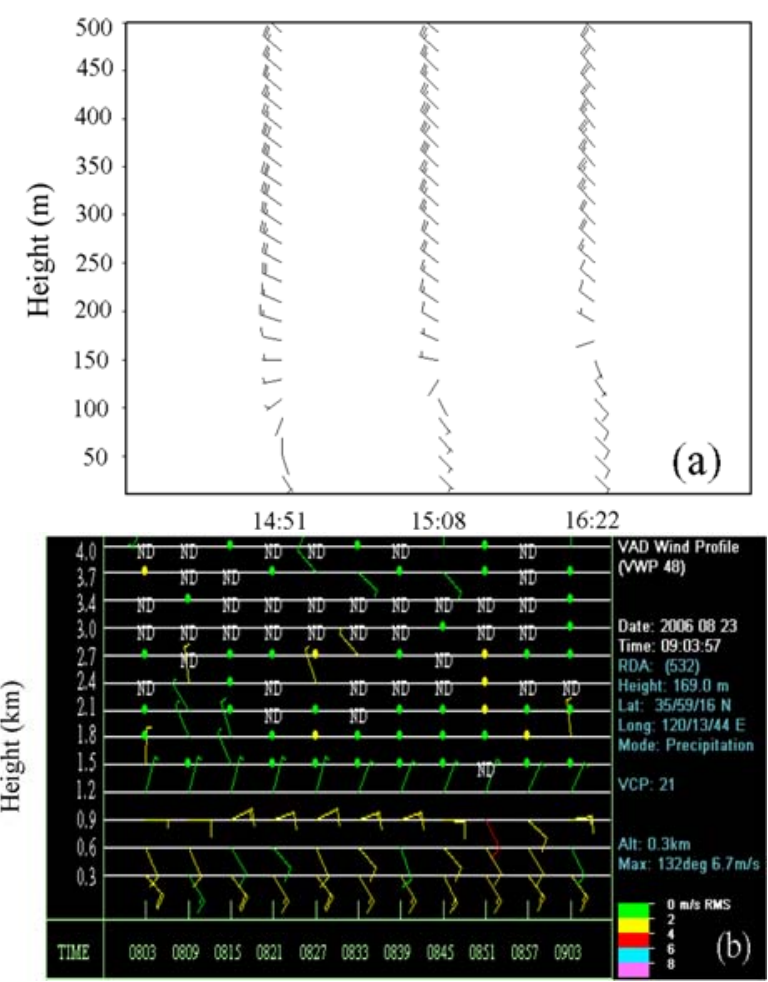

Fig. 5. Time height cross-section of low-level horizontal winds from lidar on 21 August (in LST) and (b) VAD wind profiles from Huangdao Doppler radar on $23 \mathrm{Au}-$ gust (UTC).

It can be seen that there were southeasterly winds in the shallow boundary at 1451 LST, which is the sea breeze. The northwesterly winds in the upper levels are associated with the large-scale weather system. In the morning, when the sea breeze begins, the southeasterly winds were very shallow. Even by $1451 \mathrm{LST}$, or about $3 \mathrm{pm}$, the sea breeze was only 70 to 80 meters deep. The sea breeze developed gradually in the afternoon and reached a depth of about $150 \mathrm{~m}$ by $1622 \mathrm{LST}$ on this day (Fig. 5a), indicating that the sea breeze became stronger in the middle of the afternoon.

Doppler radar Velocity Azimuth Display (VAD) wind profiles can show the mean horizontal wind profiles near the radar station. It is deployed from the 30 pixel value of the level-II Doppler radar radial velocity within a $30 \mathrm{~km}$ radius of the radar site ( $\mathrm{Yu}$ et al., 2006). Therefore the VAD wind profiles can indicate the 6-minute vertical wind change near the radar site. So far, this kind of data has not been applied in the study of sea breezes in China. The Olympic sailing spots are about $20 \mathrm{~km}$ northeast of the Huangdao radar station (Fig. 1), just within the effective radius of the VAD wind profile product. Although the vertical resolution of VAD data is relatively low, the VAD wind profiles from 9 to 31 August 2006 show clear signs of sea breeze winds in the afternoons when buoy data indicate their presence. We note that even though the radar is not located at the sailing sites, it is located on a large peninsula that is subject to a similar influence of land and sea breezes. Wind changes in the direction of VAD winds correspond well with those seen in buoys and automatic weather station data. The depth of the sea breeze is generally less than 300 meters in the VAD data during this period, a feature similar to that of the sea breeze in Longkou in the northern part of the Shandong Peninsula (Xue et al., 1995). The sea breeze can not be seen in the Huangdao Doppler radar reflectivity products (not shown) because the height of the radar is 169 meters, generally higher than the height of the sea breeze.

The sea breeze on 23 August 2006 is, however, as deep as $1 \mathrm{~km}$ (Fig. 5b). The VAD wind profiles show that the surface winds turned to southwesterly at around 0900 and $1000 \mathrm{LST}$, and to southeasterly at $1240 \mathrm{LST}$, meaning that the sea breeze is fully established by $1300 \mathrm{LST}$, which is coincident to the observation from the buoys and the automatic weather stations (AWS). At the beginning, the sea breeze is confined to below 300 meters in height. With the development of the sea breeze circulation, the height of the sea breeze increases gradually to 600 meters by 1400 LST. At around 1700 LST, the southeast sea breeze is the strongest of the day and reaches a height of about $1 \mathrm{~km}$.

\subsection{Horizontal structures of sea breezes in Doppler radar measurements}

As discussed above, the strongest sea breeze event during the Olympic test period occurred on 23 August 2006, and only this sea breeze can be clearly identified in low-level PPI (Plan Position Indicator or constant elevation) scans of the Huangdao Doppler radar. According to the Doppler radar reflectivity, at 1300 LST on 23 August, there was a thin boundary in the 0.5 degree elevation reflectivity field of the Huangdao radar. At this time, no boundary can be identified near the Jiaozhou Bay in the western part of Qingdao area. Half an hour later, this thin boundary becomes stronger and more clear. A clear boundary of green echoes and enhanced reflectivity is found running through the middle of Jiaozhou Bay in a southwest-northeast orientation (Fig. 6a). This corresponds to enhanced low-level convergence along the sea breeze front. The sea breeze can also be identified in the radial velocity field (Fig. 6b). Different from the reflectivity, the entire Jiaozhou Bay shows red radial velocities (radial wind is away from the radar site), indicating the presence of sea breeze. That is to say, there are two sea breezes, one is near the eastern part 

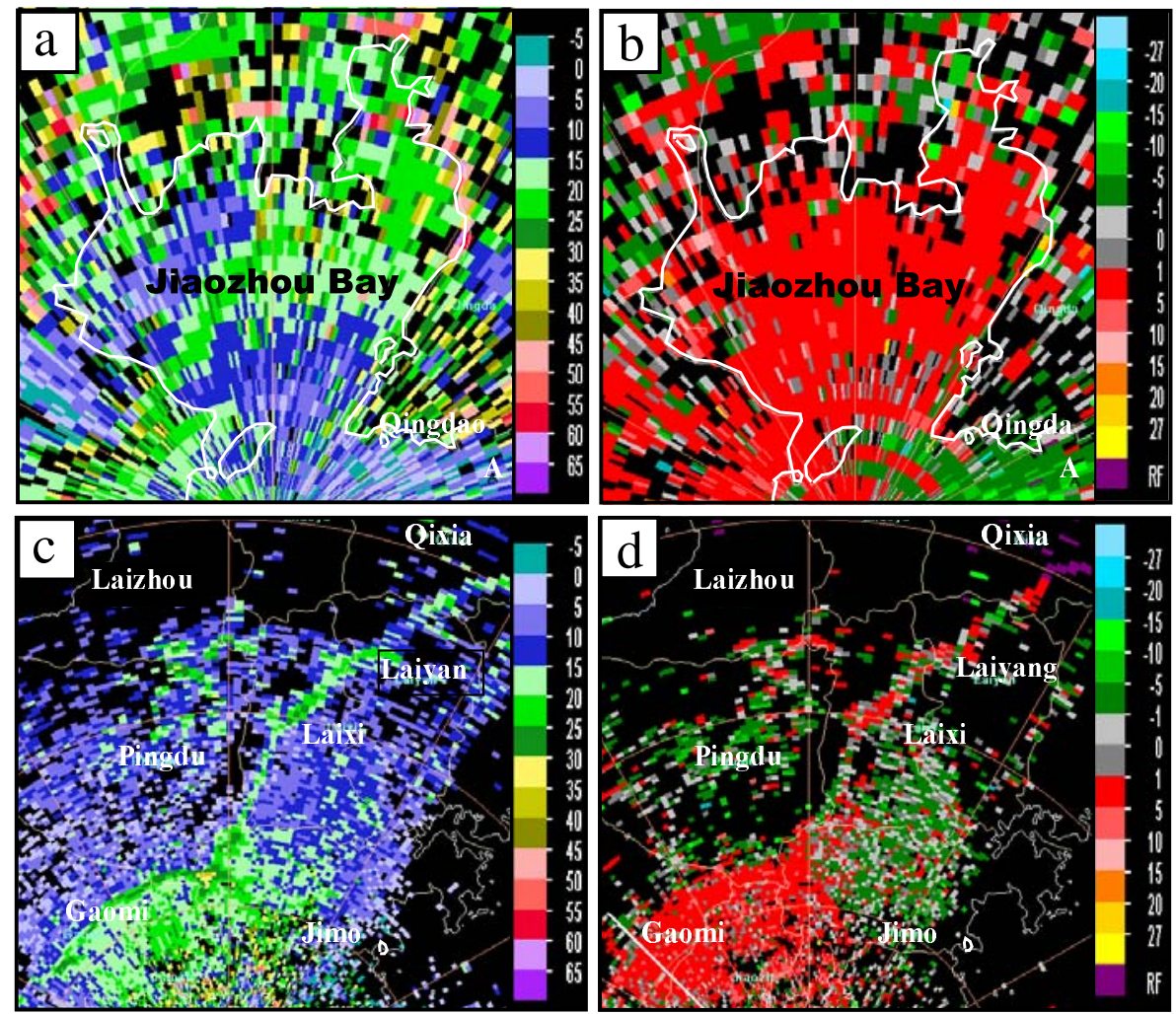

Fig. 6. Reflectivity and radial velocity images at 0.5 degree elevation from Huangdao radar, indicating the presence of sea breeze fronts. Reflectivity at (a) 1336 LST and (c) 1703 LST 23 August; radial velocity (right panels) at (b) 1336 LST and (d) 1703 LST 23 August.

of Huanghai Sea and its sea breeze front can be seen from Doppler radar, the other is from the local Jiaozhou Bay. The sea breeze near the Jiaozhou Bay is too weak to be seen in Doppler radar reflectivity but can be confirmed by data from the AWS station near Qingdao (see Fig. 7a). At around 1400 LST, the sea breeze from the Huanghai Sea travels across the Jiaozhou Bay and gradually forms a circular boundary in the radar reflectivity field. At $1500 \mathrm{LST}$, the three-boundary structure of the sea breeze can be seen clearly from the AWS data (see Fig. 7b).

By 1700 LST, the sea breeze has developed to its maximum strength and is about $100 \mathrm{~km}$ inland. Because the sea breeze front is far inland and the Jiaozhou Bay is out of Figs. $6 \mathrm{c}$ and $6 \mathrm{~d}$, it is found that the northern portion of the sea breeze front is at Qixia City (marked "Qixia" in Figs. 6c, d), and its southwestern part is at Chenggezhuang, Zhucheng City (this city is out of Figs. 6c, d). The depth of the sea breeze is up to $3 \mathrm{~km}$ according to the VAD Wind Profile in Fig. 5b. The location of the sea breeze front can be seen clearly from the radial velocity image (Fig. $6 \mathrm{~d})$. The structure of the sea breeze front can also be seen from AWS data although the data over land far from the coast are sparse (Fig. 7c).

After $1700 \mathrm{LST}$, the sea breeze becomes weaker from the northeastern part. The sea breeze front in reflectivity data disappeared gradually. At 2000 LST, the sea breeze front can still be identified in the surface chart although the short front can't be seen in the surface chart (Fig. 7d). It can be seen that the convergence line between the sea and land breezes near the sea breeze front remained even though the sea breeze has died. At this time, no sea breeze front signature can be found in the Huangdao radar data.

\subsection{The vertical structure of the sea breeze in Doppler radar measurements}

The vertical structure of the sea breeze front can also be examined using the RHI (Range-Height Indicator) radar scan data. Figure 8 shows such vertical cross sections at 1700 LST 23 August 2006 along the white line in Fig. $6 \mathrm{~d}$ that is normal to the sea breeze front. It can be seen that the sea breeze is very shallow even though this is the strongest stage of the sea breeze (around 1700 LST). There exists a region of enhanced reflectivity between the 75 and $86 \mathrm{~km}$ ranges northwest of the radar and below $1.5 \mathrm{~km}$ in height, 

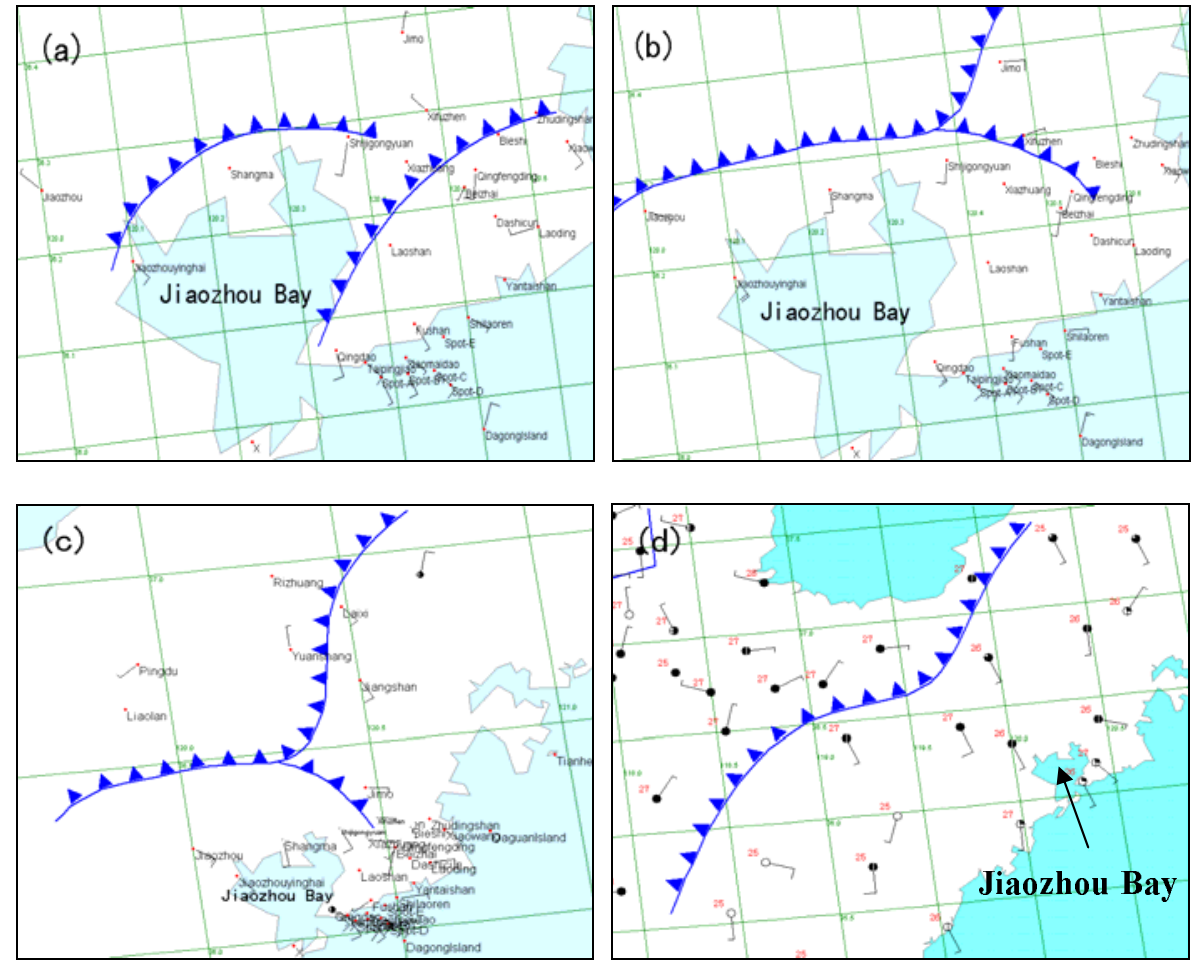

Fig. 7. Sea-breeze fronts analyzed based on AWS data at (a) 1300, (b) 1500, (c) 1700 and (d) 2000 LST 23 August 2006.

which is the region of sea breeze front edge (Fig. 8a). In the radial velocity field (Fig. 8b), a layer of outgoing radial velocity (red colors) is found below the $2 \mathrm{~km}$ level, and this depth seems to decrease to less than 1 $\mathrm{km}$ near the sea breeze front. Above this layer, the flow speed is nearly zero, and a region of reversed flow (towards radar) is found at about the $4 \mathrm{~km}$ level near the $65 \mathrm{~km}$ range. Such results are consistent with the findings with VAD data.

\section{Discussion and summary}

With data from automatic weather stations, buoys, lidar and Doppler radar that are routinely available and especially deployed for the Good Luck Beijing2006 Qingdao International Regatta that occurred from 18 to 31 August 2006 off the coast of Qingdao, Shandong Province, China, the three-dimensional structure and characteristics and diurnal evolution of sea breezes near the sites of sailing test were analyzed. The main conclusions are summarized as the following:

(1) Excluding days impacted by rain or a nearby typhoon, a sea breeze is found on all days over approximately a 20 day period in late August 2006 that covers the Olympics sailing test event. When the Qingdao coastal region is located at the edge of the subtropical high at the $500 \mathrm{hPa}$ level, the sea breeze usually starts at around 1100 to 1300 LST and lasts about 6 hours, and its wind direction tends to be southeasterly. When the region is under the control of the subtropical high, the sea breeze usually begins later between 1300 and $1500 \mathrm{LST}$, and the sea breeze wind direction is easterly to southeasterly.

(2) Under the control of the subtropical high, the winds at all three spots are weak and remain below $2.5 \mathrm{~m} \mathrm{~s}^{-1}$ on average and the wind direction is more variable. The wind direction is generally easterly to southeasterly. The sea breeze found at the edge of the subtropical high is stronger. The mean wind speed is $3-4 \mathrm{~m} \mathrm{~s}^{-1}$ in this case and the sea breeze direction is usually southeasterly and normal to the coastline. If the sea breeze wind speed is stronger, its direction tends to be more close to the normal direction of the coastline. Otherwise, the direction is closer to the direction of the systematic or background wind.

(3) In general, the difference in the sea and land air temperature is over $4^{\circ} \mathrm{C}$ for the sea breeze days. The subtropical high can affect the sea breeze due to the difference in the prevailing wind. At the edge of the subtropical high at the $500 \mathrm{hPa}$ level, the prevailing wind in Qingdao is usually northerly and it can act as the return circulation of the sea breeze. Therefore, the northerly prevailing wind can help the establishment of the sea breeze, thus the sea breeze is stronger and 

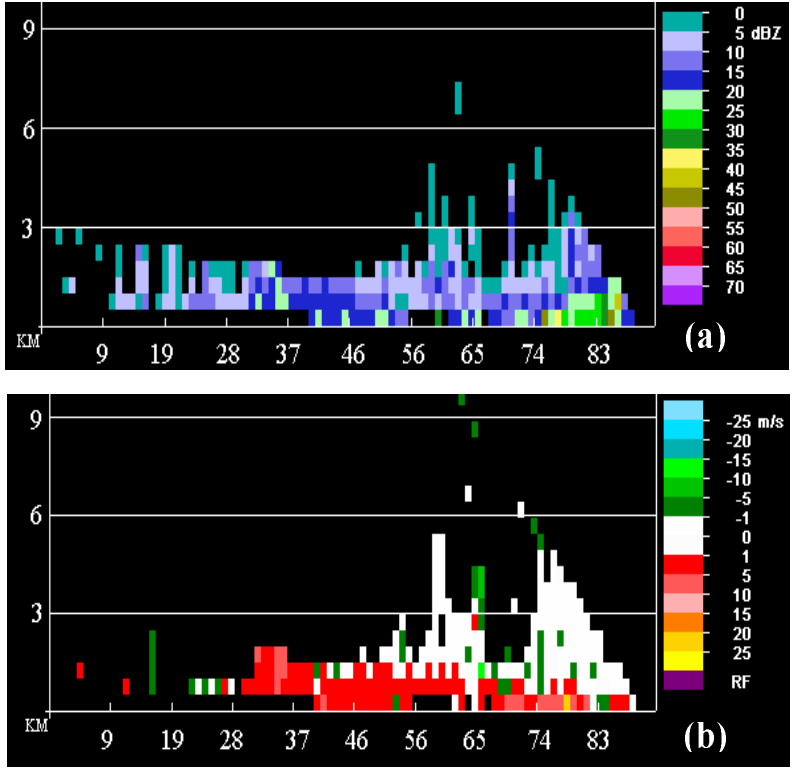

Fig. 8. (a) Vertical cross-section (RHI display) of Doppler radar reflectivity and (b) radial velocity normal to the sea breeze front at 1700 LST 23 August 2006. The radar is located at the lower-left corner of the plots.

begins earlier.

(4) The depth of the sea breeze is usually very shallow and is held to below 300 meters. For stronger sea breezes, it can be $1.5 \mathrm{~km}$ deep and can push inland as far as $100 \mathrm{~km}$. If the Huanghai sea breeze propagates inland and meets the sea breeze of the Jiaozhou Bay on its western part, the sea breeze will strengthen and form a three-boundary structure as a result of the interaction between the two sea breeze systems.

As discussed above, excluding the maximum daily temperature difference, the large scale weather pattern can affect the strength of the sea breeze too. When the Qingdao coastal region is at the edge of the subtropical high (EDGE period), Qingdao tends to be affected by weak cold air and the prevailing wind is usually northerly in the morning (see Fig. 3f), which is same as the direction of the sea breeze return circulation. Once the land-sea temperature difference is large enough (usually over $4 \mathrm{~K}$ ), the surface wind will change from sea to land and the prevailing wind can act as the sea breeze return circulation and help the establishment of the sea breeze, therefore, the sea breeze is stronger and begins earlier. Under the control of the subtropical high, the temperatures over the land and sea are both high and the associated strong heating in the daytime results in more mixing near the surface, therefore, the wind is light and wind direction more variable over the entire day. In this situation, the easterly wind is not favorable to the establishment of the sea breeze winds and the sea breeze is weaker.
Furthermore, the directions of sea breeze for the CNTL and EDGE days are slightly different as well. For the sea breeze in EDGE days, the direction is southeasterly, which is normal to the coastline. In CNTL days, the direction of the sea breeze is from easterly to southeasterly, closer to the systematic wind direction (see Fig. 3e). This may be caused by the difference of the prevailing wind and the difference of the sea breeze strength. If the sea breeze is stronger, its direction is closer to the normal direction of the coastline. If the sea breeze wind speed is weaker, its direction is closer to the direction of systematic or background winds. In Houghton and Campbell (2005), the sea breeze starts at right angles to the coast and veers (shifts anticyclonically) until sunset, to become nearly parallel to the coastline. As discussed in this study, the "veering" feature of the sea breeze documented in Houghton and Campbell (2005) for the coastal region does not happen in Qingdao region.

Because of the significance of the Qingdao coastal region in the upcoming Olympic events in summer 2008 , and the general lack of detailed studies on the essentially daily sea breeze events, especially those using special observational data, we believe that this study represents an important step towards better understanding and eventual improved prediction of land and sea breezes in this region.

Acknowledgements. The authors thank Jianlin Wang of Qingdao Municipal Meteorological Bureau for providing some of the data used in this study. This work was mainly supported by National Natural Science Foundation of China Grant (Grant No. 40705017), the Chinese Academy of Sciences Grant (Grant No. 2004-2-7) and the Natural Science Foundation of Shandong Province Grant (Grant No. Q2007E03). Special thanks go to Prof. Gang $\mathrm{Fu}$, Ocean University of China and an anonymous reviewer, for their constructive suggestions that improved this paper significantly.

\section{REFERENCES}

Arritt, R. W., 1993: Effects of the large-scale flow on characteristic features of the sea breeze. J. Appl. Meteor., 32, 116-125.

Barbato, J. P., 1975: The sea breeze of the Boston area and its effect on the urban atmosphere. Ph. D. Dissertation, Boston University, 223pp.

Bechtold, P., J.-P. Pinty, and P. Mascart, 1991: A numerical investigation of the influence of large-scale winds on sea-breeze-and inland-breeze-type circulations. $J$. Appl. Meteor., 30, 1268-1279.

Buckley, R. L., and R. J. Kurzeja, 1997: An observational and numerical study of the Nocturnal sea breeze. Part I: Structure and Circulation. J. Appl. Meteor., 36, 1577-1598. 
Chang, Z. Q., Z. M. Wu, and S. H. Gao, 2002: Simulation of the three-dimensional structure of sea and land breeze in Qingdao. Periodical of Ocean University of China, 6, 877-883. (in Chinese)

Clarke, R. H., 1984: Colliding sea-breezes and the creation of internal atmospheric bore wafes: Twodimensional numerical studies. Australian Meteorological Magazine, 32, 207-226.

Defant, A., 1951: Local winds. Compendium of Meteorology. T. F. Malone, Ed., Amer. Mereor. Soc., 658-672.

Estoque, M. A., 1961: A theoretical investigation of the sea breeze. Quart. J. Roy. Meteor. Soc., 17, 645-660.

Estoque, M. A., 1962: The sea breeze as a function of the prevailing synoptic situation. J. Atmos. Sci., 19, 244-250.

Frizzola, J. A., and E. L. Fisher, 1963: A series of sea breeze observations in the New York City area. $J$. Appl. Meteor., 2, 722-739.

Haurwitz, B., 1947: Comments on "The sea-breeze circulation." J. Meteor., 4, 1-8.

Houghton, D., and F. Campbell, 2005: Wind Strategy. Fernhurst Books, England, 128pp.

Jin, H., and Y. C. Wang, 1991: Simulation of the three sea breeze. Chinese J. Atmos. Sci., 15, 25-32. (in Chinese)

Neumann, J., 1977: On the rotational rate of the direction of sea and land breezes. J. Atmos. Sci., 34, 19131917.

Reible, D. D., J. E. Simpson, and P. F. Linden, 1993: The sea breeze and gravity-current frontogenesis. Quart. J. Roy. Meteor. Soc., 119, 1-16.

Schroeder, M. J., M. A. Fosberg, O. P. Cramer, and C. A. O'Dell, 1967: Marine air invasion of the Pacific coast: A problem analysis. Bull. Amer. Meteor. Soc.,
48, 802-808.

Sha, W., T. Kawamura, and H. Ueda, 1991: A numerical study on sea/land breezes as a gravity current: Kelvin-Helmholtz billows and inland penetration of the sea-breeze front. J. Atmos. Sci., 48, 1649-1665.

Staley, D. O., 1957: The low-level sea breeze of northwest Washington. J. Meteor., 14, 458-470.

Wakimoto, R. M., and N. T. Atkins, 1993: Observations of the sea-breeze front during CaPE. Part I: SingleDoppler, satellite, and cloud photogrammetry analysis. Mon. Wea. Rev., 122, 1092-1114.

Wexler, R., 1946: Theory and observations of land and sea breezes. Bull. Amer. Meteor. Soc., 27, 272-287.

Wu, Z. M., and B. S. Long, 1993: Analysis of the local wind in Qingdao. Ocean and Lake Bulletin, 16-21. (in Chinese)

Xue, D. Q., Q. L. Zheng, and X. Z. Qian, 1995: Sea breeze and its effect in Longkou. Ocean and Lake Bulletin, 1-9. (in Chinese)

Yu, X. D., X. P. Yao, T. N. Xiong, X. G. Zhou, H. Wu, B. S. Deng, and Y. Song, 2006: The Principle of Doppler Weather Radar. China Meteorological Press. 40-51. (in Chinese)

Zhang, Y., Y. Chen, and T. A. Schroeder, 2005: Numerical simulation of sea-breeze circulation over Northwest Hawaii. Wea. Forecasting, 20, 827-846.

Zhong, S., and E. S. Takle, 1993: The effects of largescale winds on the sea-land-breeze circulations in an area of complex coastal heating. J. Appl. Meteor., 32, 1181-1195.

Zhuang, Z. S., M. Q. Zheng, J. X. Wang, X. J. Zhou, and M. K. Zhang, 2005: Climate feature of sea breeze in Rizhao and it's effect on local weather. Meteorological Monthly, 31, 66-70. (in Chinese) 